\author{
International Journal of Advances in Life Science and Technology \\ 2014. Vol.1, No.1, pp. 1-5 \\ $\operatorname{ISSN}(e): 2313-8335$ \\ $\operatorname{ISSN}(p): 2412-3803$ \\ DOI: 10.18488/journal.72/2014.1.1/72.1.1.5 \\ (C) 2014. Conscientia Beam. All Rights Reserved. \\ (1) Crossmark
}

\title{
TESTICULAR DOSES OF PATIENTS UNDERGOING RADIOLOGICAL EXAMINATION OF THE CHEST AT FEDERAL MEDICAL CENTRE MAKURDI, NIGERIA
}

\author{
L. Alumuku' --- J.T. Iortile ${ }^{2}$--- E.H. Agba ${ }^{3}$ \\ ${ }^{\prime}$ Department of Pure and Applied Physics, Federal University of Wukari, Taraba State Nigeria \\ ${ }^{2}$ Department of Radiology, Benue State University Makurdi, Benue State, Nigeria \\ ${ }^{3}$ Deparment of Physics, Benue State University Makurdi, Benue State, Nigeria
}

\begin{abstract}
The testicular dose of eight adult male patients undergoing radiological examination of the chest were investigated at the radiological department of the Federal Medical Center (FMC) Makurdi using themoluminescent dosimetry technique. The investigation was carried out using LiF TLD discs Reader, TLD model 4500 (Harshaw Radiation measurement product USA), 3-phase diagnostic X-ray machine and single a phase X-ray machine. The Mean testicular dose of the male patients investigated was found to be $0.0662 \pm 0.0034 m G y$. There is also a significant correlation between testicular dose and tube potential, in which higher tube potential delivered higher values of testicular doses. Results showed that, testicular doses are within acceptable limits, which is approximately $6.6 \%$ of the $1 \mathrm{mGy}$ reference dose level.
\end{abstract}

Keywords: Testicular doses, X-rays, Thermoluminescent dosemeters, Radiation, Exposure, Patients.

\section{INTRODUCTION}

Medical physicists have become more concerned recently about the somatic and genetic hazard associated with radiation exposure and absorbed dose to patients during chest radiographic examination [1]. Diagnostic radiology requires that measurement be made of the radiation dose received by patients during diagnostic procedures and this has come under scrutiny and monitoring in recent times [2].

In both developed and developing countries, the number of X-rays facilities and X-rays equipment is increasing rapidly [3]. Although alternative modalities for diagnostic of diseases and injuries, such as ultrasound and Magnetic Resonance Imaging (MRI) are becoming increasingly available. Steady improvements in the quality of X-ray images and patients protection have ensured that the use of diagnostic X-rays remain the most used technique for diagnosis [4].This makes it a major contributor to man's exposure to artificial sources of ionizing radiation. Medical physicists have devoted much attention to the minimization of patients' dose in 
diagnostic radiology. Substantial reduction in radiation dose to the patients resulting from radiographic procedures have been achieved in many countries [1].

Radiology personnel cannot quantitatively monitor dose to the patients in every procedure, however, the magnitude of patients exposure resulting from the various radiological examinations performed must be appreciated [5]. The objective of radiological examinations is to obtain information about the internal anatomy of patients in order to provide adequate diagnostic data for clinician [6]. Chest radiography examination is the most frequently performed radiological procedure in Nigeria, which contributes to the most common use of X-rays leading to high population dose of medical irradiation. In chest radiography, testes are outside the exposed field, it would be very useful for clinical radiographers to know how and to what extent the testicular doses vary with tube potential in chest radiography, using both the high tube potential and the tube potential techniques. This knowledge will lead to appropriate exposure selection consistent with acceptable image quality [7].

The objectives of this research is to measure the entry dose to the testes of adult patients during radiological examination of the chest, at the Federal Medical center Makurdi, Nigeria and compare the doses to the reference dose level of $1 \mathrm{mGy}$ as recommended by the International Commission on Radiological Protection (ICRP) and to suggest ways of reducing testicular dose during chest X-ray examinations.

\section{MATERIALS AND METHOD}

This study was carried out at the radiology department of the Federal Medical center Makurdi, Nigeria. 8 adult males were considered and measurement of the scattered X-ray dose to the testes was carried out based on thermoluminescent dosimeter technique (TLD) using TLD 4500 (Harshaw radiation measurement product USA) with disc sharp pallets of $4.5 \mathrm{~mm}$ diameter and $0.8 \mathrm{~mm}$ thickness. The TLD discs, which were annealed at the National Institute of Radiation and Research, University of Ibadan, Nigeria were enclosed in plastic covers and positioned at the testes of the male patients. This was removed immediately after examination so that entry testes dose were measured. The radiolographic view considered was posteroanterior while chest X-ray for each patient was made at different peak tube voltage $(\mathrm{kVp})$ and source to skin distance (SSD).

The calibration of the TLD discs were done at the National Institute of Radiation and Research, University of Ibadan which enabled the translation of the final corrected counts for the read phase into the appropriate radiation dose in $\mathrm{mGy}$.

\section{RESULTS AND DISCUSSION}

The result of study has provided useful information about the $\mathrm{kVp}$ and the amount of doses received by patients during chest radiological examination (Table 2.0).

Figure 1.0 shows that testicular doses increases with tube potential. This is because the peak voltage across the $\mathrm{X}$-ray tube $(\mathrm{kVp})$ increases the energy of the $\mathrm{X}$-rays in the beam, which produces more absorbed energy in the gonads due to the increased scattering ability of the X- 
rays. This in turn means that a greater number of X-rays will be produced at the target, and thus, the intensity of the beam will also be increased as reported by Graham and Francis [8].

High tube potential is not recommended in chest radiography since it delivers significantly higher doses to testes and the produced X-rays will be scattered to greater distances. It also produces a lower contrast film, thus deteriorating the diagnostic value. According to Fung and Gilboy [7], it is important to use a low tube potential technique as this will definitely deliver significantly lower testicular doses.

The study also revealed that testicular doses obtained by TLD measurements decreases with increase in chest thickness (Fig. 2.0). This trend appears to suggest that the amount of X-rays absorbed by the patient is dependent on size of the patients. With increase in the patient chest thickness, more X-rays are absorbed and less X-rays are scattered to the testes.

The mean testicular dose of the male patients investigated was $0.0662 \mathrm{mGy}$ obtained at Federal Medical Centre Makurdi, Nigeria approximately 6.6\% of the $1 \mathrm{mGy}$.

An increase in the peak voltage across the X-ray tube increases the maximum energy of the $\mathrm{X}$-ray in the beam. The results also indicates that testicular doses increases with a decrease in chest thickness and this agrees with the published work of Fung and Gilboy [7] and Ajayi and Oresegun [10].

\section{CONCLUSION}

These doses are well within acceptance limits [10]. From the point of view of stochastic risk of radiation, the individual risk due to these doses is quite low. However, care must be taken for the patients who are repeatedly undergoing radiological examination of the chest.

\section{ACKNOWLEDGEMENT}

We wish to acknowledge the contributions of the staff of the Radiology Department of the Federal Medical Centre Makurdi, Nigeria

\section{REFERENCES}

[1] F. O. Ujah, N. B. Akaagerger, E. H. Agba, and J. T. Iortile, "A comparative study of patients radiation levels with standard diagnotistic reference levels in federal medical centre and Bishop Murray hospitals in Makurdi," Archives of Applied Science Research, vol. 4, pp. 800-804, 2012.

[2] S. Mattson, "Principles of radiation protection in medicine," In proceeding of College of Medical Physics organized by International Centre for Theoretical Physics (ICTP), Trieste, Italy, 1994.

[3] United Nations Scientific Committee on the Effects of Atomic Radiation (UNSCEAN), "Hereditary Effects of Radiation. Report to the General Assembly," United Nations, New York, 2001.

[4] International Atomic Energy Agency (IAEA), Dosimetry in diagnostic radiology: An International Code of Practice IAEA Vienna, 2007.

[5] International Commission on Radiation Units and Measurement, "Patient dosimetry for X-rays used in medical imaging," ICRU Bethesda, MD ICRU Rep.741990. 
[6] P. C. Shrimpton and B. F. Wall, "The increasing importance of X ray computed tomography as a source of medical exposure," Radiation Protection Dosimetry, vol. 57, pp. 413-415, 1995.

[7] K. K. Fung and W. B. Gilboy, "The effect of beam tube potential variation on gonad dose to patients during chest radiology investigated using high sensitivity $\mathrm{LiF}: \mathrm{Mg}, \mathrm{Cu}, \mathrm{P}$, thermoluminescient dosemeters," Br. J. Radiol, vol. 74, pp. 358-67, 2001.

[8] H. Graham and A. Francis, Medical physics for advanced level: Simon and Schuster Education Press Maryland Avenue, 1992.

[9] ICRP, "Recommendations of international commission on radiological protection," Annals of the ICRP, vol. 194, 1991.

[10] I. R. Ajayi and M. O. Oresegun, "Gonadal dose to patients from chest X-ray examination," Nigeria Journal of Physics, vol. 6, pp. 42-43, 1994.

Table-1. The specifications of the x-ray machines used.

\begin{tabular}{|c|c|c|}
\hline Name of X-ray machine & Watson & Medtronic \\
\hline Manufacturer & $\begin{array}{l}\text { GEC medical equipment LTD } \\
\text { England }\end{array}$ & $\begin{array}{l}\text { GEC medical equipment } \text { LTD } \\
\text { Wembly Middlesex England }\end{array}$ \\
\hline Total Tube filtration (mmAI) & 1.5 & 2.1 \\
\hline $\mathrm{SSD}(\mathrm{cm})$ & 190 & 190 \\
\hline Radiographic view Kv range & PA & PA \\
\hline Kv range & 45-120 Max & 0-120Max \\
\hline MAS (variable) & $0-500$ & o-120max \\
\hline
\end{tabular}

Table-2.The testicular dose and radiographic parameters during posteroanterior chest radiography examinations of the patients using a three-phase x-ray machine.

\begin{tabular}{|c|c|c|c|c|c|c|c|c|c|}
\hline $\mathbf{S} / \mathbf{N}$ & Age & $\mathrm{kVp}$ & MAS & $\begin{array}{l}\text { FSD } \\
{[\mathrm{CM}]}\end{array}$ & $\begin{array}{l}\text { SSD } \\
{[\mathrm{CM}]}\end{array}$ & $\begin{array}{l}\text { Chest } \\
{[\mathrm{cm}]}\end{array}$ & Thickness & $\begin{array}{l}\text { Testicular } \\
\text { mGy }\end{array}$ & Dose \\
\hline 1 & 43 & 72 & 20 & 159 & 140 & 19 & & \multirow{8}{*}{$\begin{array}{l}0.0620 \\
0.0552 \\
0.0780 \\
0.0640 \\
0.0700 \\
0.0593 \\
0.0823 \\
0.0604\end{array}$} & \\
\hline 2 & 40 & 69 & 20 & 166 & 145 & 21 & & & \\
\hline 3 & 35 & 78 & 13 & 158 & 142 & 16 & & & \\
\hline 4 & 22 & 73 & 20 & 138 & 120 & 18 & & & \\
\hline 5 & 25 & 75 & 13 & 159 & 142 & 17 & & & \\
\hline 6 & 31 & 70 & 60 & 142 & 122 & 20 & & & \\
\hline 7 & 35 & 79 & 80 & 140 & 125 & 15 & & & \\
\hline 8 & 37 & 71 & 80 & 150 & 130 & 20 & & & \\
\hline
\end{tabular}


International Journal of Advances in Life Science and Technology, 2014, 1(1): 1-5

Fig-1.Variation of testicular dose with tube potential

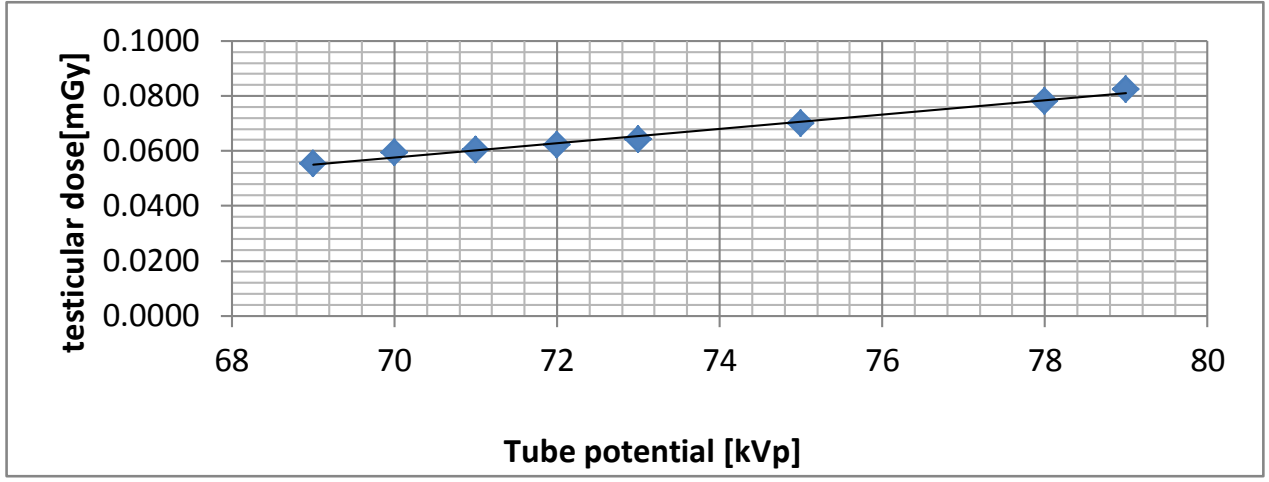

Fig-2.Variation of testicular dose with Chest thickness

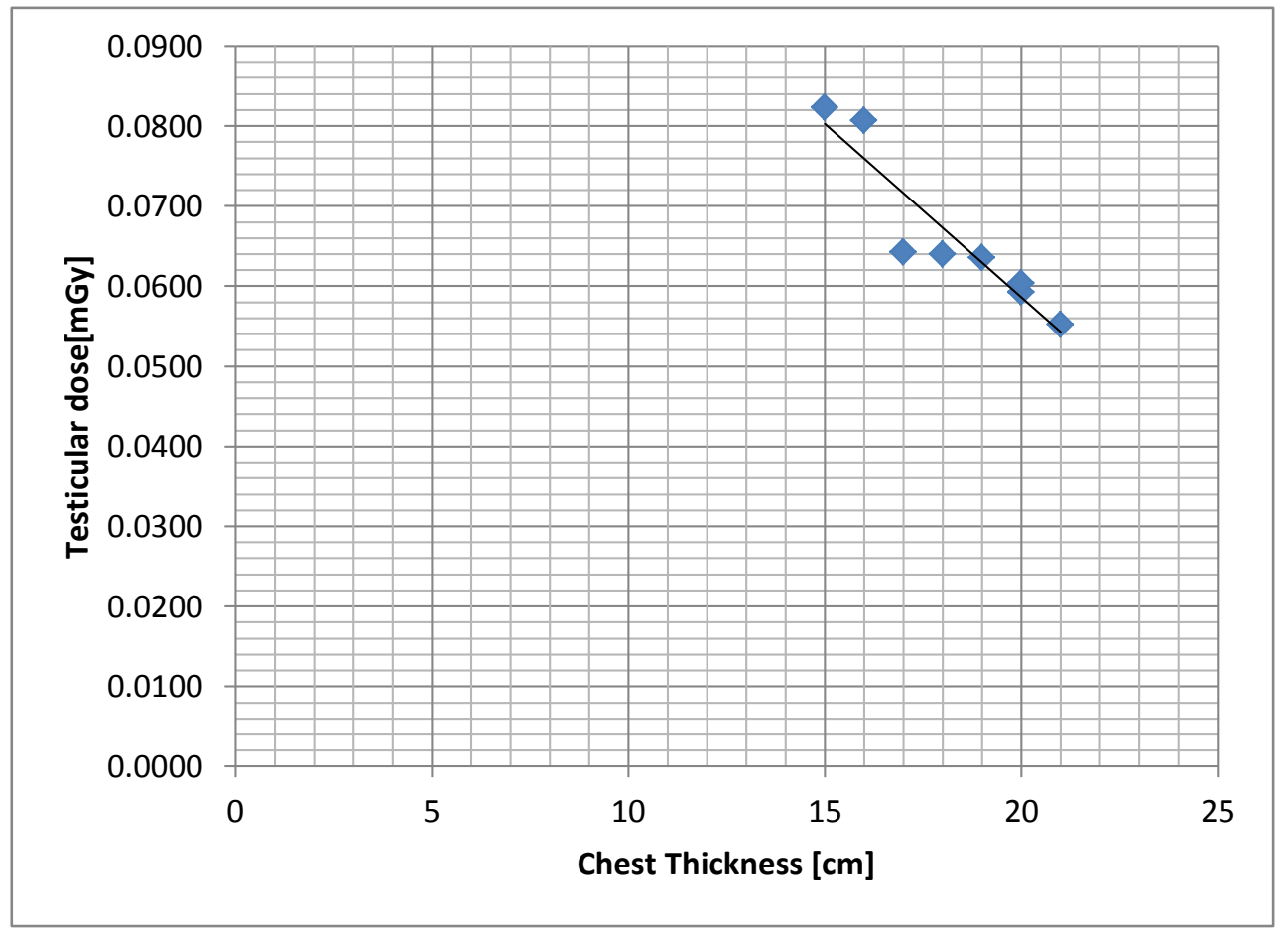

Views and opinions expressed in this article are the views and opinions of the author(s), International Journal of Advances in Life Science and Technology shall not be responsible or answerable for any loss, damage or liability etc. caused in relation to/arising out of the use of the content. 